\title{
Assessment of the Effects of Occluding Pairs of Teeth on Oral Health-related Quality of Life among Dialysis Patients
}

\author{
Payal Kahar ${ }^{1}$, Carol A Chapman², Sachi Brahmbhatt ${ }^{3}$, Deepesh Khanna ${ }^{4}$
}

\begin{abstract}
Aim: To determine oral health-related quality of life (OHRQoL) in hemodialysis patients and assess if location and distribution of teeth had perceived oral impacts.

Materials and methods: Face-to-face interviews and oral examinations were conducted among 96 patients in southwest Florida. Sociodemographic data in addition to self-reported medical conditions were collected. OHRQoL was determined using the Geriatric Oral Health Assessment Index (GOHAl-12). Presence of decayed teeth, missing teeth, anterior occluding pairs (AOPs) and posterior occluding pairs (POPs), and community periodontal index were ascertained through oral examinations.

Results: Mean age was $64.81 \pm 12.9$ years. Mean number of teeth present was $20.12 \pm 10.8$. Nearly half (48\%) of the participants had $\geq 1$ decayed teeth. Among those examined for periodontal health, $86 \%$ had some form of periodontal disease. Mean AOP was $4.4 \pm 2.3$ and mean POP was 4.2 \pm 3.1. Median GOHAl-12 score was 52. Limiting the kinds or amounts of food $(p=0.040)$, trouble biting or chewing $(p=0.010)$, feeling uncomfortable eating in front of people $(p=0.024)$, and pleased with looks $(p=0.038)$ were statistically significant for AOP groups. Only trouble biting or chewing $(p=0.044)$ and pleased with looks showed significant association with POP groups $(p=0.038)$. In adjusted regression analyses, participants with AOPs 0 to 2 had $86 \%$ lower odds of reporting GOHAI- 12 scores above 40 (25th percentile) than the group with AOPs 3 to 6 (odds ratio $=0.14 ; 95 \%$ confidence interval $=0.04-0.58$ ).

Conclusion: The study highlights fewer AOP to have a larger effect than POP not only in the psychosocial dimension but also in the functional abilities. Lower GOHAl-12 scores were associated with AOP 2 or less than 2 in the study sample.

Clinical significance: While treatment and management of oral health problems in dialysis patients are complicated by the presence of co-morbidities, age-related changes in the mouth, and issues of access to dental care, identification, repair, or replacement of strategically important teeth using the "shortened dental arch principle" to maintain oral function among hemodialysis patients are recommended.

Keywords: Dental health surveys, Dental prosthesis, Dialysis, Oral health, Quality of life, Tooth loss.

The Journal of Contemporary Dental Practice (2021): 10.5005/jp-journals-10024-3046
\end{abstract}

\section{INTRODUCTION}

Oral status and systemic health are bidirectionally related. Systemic changes in patients with chronic diseases affect oral health and vice versa. ${ }^{1}$ The maintenance of general health is complex among hemodialysis patients due to increased susceptibility to infections as well as a chronic inflammatory state. Co-morbidities, associated with the need for hemodialysis, frequently exacerbate the inflammatory cascade leading to a more severe materialization in the oral cavity. Dialysis patients in previous studies ${ }^{2-4}$ have shown to have periodontal diseases, high decayed, missing, filled teeth (DMFT) index, and accumulation of calculus. While the prevalence of oral diseases may be higher in dialysis patients, objective assessment in terms of frequency and severity of diseases fails to capture health status. It does not adequately describe functional and psychosocial aspects of oral health as well as perceived treatment needs of the individuals. ${ }^{5,6}$ As such, investigation of contextual factors that contribute to the bidirectional relationship between oral and general may provide guidance for future intervention efforts.

Quality of Life (QoL) has gained recognition as a significant contributor to treatment outcomes in individuals with various conditions. ${ }^{7,8}$ The adaptive ability (resiliency) and personal characteristics influence an individual's response to chronic diseases. ${ }^{9}$ QoL concept applied to oral health has largely focused on untreated caries, periodontal diseases resulting in tooth loss that affect masticatory abilities, social interactions, and esthetics. ${ }^{10}$
${ }^{1}$ Department of Health Sciences, Marieb College of Health \& Human Services, Florida Gulf Coast University, Fort Myers, Florida, United States

${ }^{2}$ Department of Dental Hygiene, Florida Southwestern College, Fort Myers, Florida, United States

${ }^{3}$ Operative Department, Program of Restorative Dental Science, College of Dentistry, University of Florida, Gainesville, Florida, United States

${ }^{4}$ Department of Basic Sciences, Dr. Kiran. C. Patel College of Osteopathic Medicine, Nova Southeastern University, Clearwater, Florida, United States

Corresponding Author: Payal Kahar, Department of Health Sciences, Marieb College of Health \& Human Services, Florida Gulf Coast University, Fort Myers, Florida, United States, Phone: 239-745-4482, e-mail: pkahar@fgcu.edu

How to cite this article: Kahar P, Chapman CA, Brahmbhatt $S$, et al. Assessment of the Effects of Occluding Pairs of Teeth on Oral Healthrelated Quality of Life among Dialysis Patients. J Contemp Dent Pract 2021;22(2):156-161.

Source of support:The study was funded by Marieb College of Health \& Human Services Inter-Professional Practice Grant 2016-2017.

Conflict of interest: None

Studies ${ }^{11-14}$ have shown perceived oral health status, and treatment needs to vary widely with such clinical measures. While clinical indicators such as number of decayed teeth or presence of 
periodontal diseases did not significantly affect perceived oral impacts, perception of oral function and social well-being were significantly associated with the number and location of missing teeth such as missing teeth or anterior/posterior occluding pair (AOP/POP) of teeth. ${ }^{11-14}$ Thus, the association of location and distribution of occluding pairs and its association with Oral HealthRelated Quality of Life (OHRQoL) represents an important area of investigation. To date, OHRQoL has been assessed using several validated questionnaires, yet the Geriatric Oral Health Assessment Index (GOHAl-12) has been widely used. ${ }^{15,16}$

Evaluation of the extent to which clinical indicators such as occluding pairs that measure functionality accurately affect perceived oral health in dialysis patients has not been adequately explored. ${ }^{12,13,17-20}$ Therefore the objective of the study was to determine OHRQoL in hemodialysis patients and assess if location and distribution of teeth had an impact on subjective experiences.

\section{Methods}

\section{Study Population}

Patients above the age of 18 years receiving hemodialysis from five different dialysis centers in southwest Florida were invited to participate. Patients reporting a past medical history of neurological, cognitive, or psychiatric conditions were excluded. Of 160 patients recruited, 96 consented to participate. However, two opted to not partake of an oral examination and one did not complete face-to-face interview. A priori power calculation indicated a sample size of $96 . .^{3,11}$ The study was approved by the institutional review boards at two institutions of higher education and a kidney care provider. Local approvals were obtained from individual dialysis centers and written consent from dialysis patients was obtained prior to participation in the study.

\section{Data Collection}

Data were collected from the GOHAl-12 questionnaire by two interviewers and clinical oral examinations were carried out by dental personnel. The 12 items in GOHAl-12 assess impacts associated with oral diseases in physical function, pain and discomfort, and psychosocial function. Participants were asked if they have always, very often, often, sometimes, seldom, or never experienced any of those problems. Responses were scored on a scale ranging from 0 (always) to 5 (never) except for three positively directed questions that were scored 5 (never) to 0 (always). The total scores ranged from 0 to 60 with higher scores indicating better health. Cronbach's alpha for GOHAI-12 items was 0.90. In addition to GOHAl-12 items, the face-to-face interviews included sociodemographic data such as sex, age, race/ethnicity, selfreported data such as the presence of morbidities, for instance, diabetes, hypertension, cancer, heart disease, and finally, number of years on dialysis. Age was categorized as less than 65 years and 65 years or more. The number of years on dialysis was grouped as 0 to 3 and greater than 3 years.

Dental personnel performed oral examinations the same day as the face-to-face interviews took place. Portable lights and prepackaged sterilized instruments were used. The examinations based on 28 teeth looked for DMFT. Dental decay was determined if a lesion in a tooth had a definite cavity, undermined enamel, or a softened floor or wall. ${ }^{22}$ Community Periodontal Index $(\mathrm{CPI})$ ranging from 0 to $4(0=$ healthy; $1=$ bleeding on probing; 2 = calculus; 3 = pocket 4 to $5 \mathrm{~mm} ; 4$ = pocket $6 \mathrm{~mm}$ or more) was ascertained in the six sextants of the oral cavity except in those cases where there were no index teeth to examine. The highest value noted in the six sextants was considered the overall $\mathrm{CPI}^{22}$ In case of missing natural teeth, the presence and types of prostheses (fixed or removable) were recorded. ${ }^{22}$ Filled teeth were determined if teeth had restorations and were categorized into four groups: No fillings, 1 to 3 teeth, 4 to 8 teeth, and 9 and above. The number of teeth present was dichotomized into two groups, less than 19 and 20 or more based on the evidence that oral function greatly diminishes with less than 20 teeth. ${ }^{23,24}$ Occluding pairs of teeth were defined as opposing pairs of natural or restored teeth as well as fixed and removable (functional) prostheses. Postcanine opposing pairs were POP while opposing pairs in the anterior region were defined as AOP. Carious teeth with extensive coronal destruction were excluded in the occluding pair calculation. AOPs were categorized as 0 to 2 and 3 to 6 while posterior teeth were divided into two groups 0 to 3 and 4 to $8 .^{12}$ Previous studies ${ }^{12,25}$ on occluding pairs suggest more oral health impacts experienced in individuals with 0 to 2 AOP and 0 to 3 POP.

\section{Data Analysis}

The statistical analysis was done using SPSS software (IBM Corp., version 26, Armonk, NY). Descriptive statistics are presented as counts and percentages in various demographic and clinical categories. Since GOHAI-12 scores were not normally distributed, Mann-Whitney $U$ tests were conducted to compare item scores and GOHAl-12 dimensions with AOP and POP groups. To conduct binary logistic regression, the sample was dichotomized in terms of GOHAI-12 scores into those who had a GOHAI-12 score below 25th percentile and those with total score above 25th percentile. This was based on the frequency distribution and the assumption that those with GOHAI-12 scores below 25th percentile had higher prevalence of oral impacts. Multiple logistic regression analyses were conducted to examine the associations between dichotomized GOHAI-12 and one clinical variable at a time such as number of teeth, decayed teeth, filled teeth, AOP, and POP for the effect of age, sex, race/ethnicity, presence of co-morbidities, and years on dialysis. Only those clinical variables that showed statistically significant associations in bivariate analyses were included in the adjusted regression analyses.

\section{Results}

Table 1 shows demographic, general, and oral health status. The mean age of the patients was $64.81 \pm 12.9$ years. There were more males (60\%) than females (40\%). Forty-eight percent of the participants reported nonHispanic white race/ethnicity, 37.5\% nonHispanic black, $11.5 \%$ Hispanic, and 2.1\% American Indian. Mean years on dialysis was $4.34 \pm 6.6$ years. Approximately $60 \%$ reported having one condition while $40 \%$ reported having more than one medical condition. Hypertension and diabetes were the most commonly reported medical conditions followed by the presence of both diabetes and hypertension. Mean number of teeth present was $20.12 \pm 10.8$. Mean number of decayed teeth was $1.5 \pm 2.7$. Nearly half (47\%) of the participants had one or more decayed teeth. Among the 58 patients examined for periodontal health, $86 \%$ had some form of periodontal disease. Nearly $47 \%$ of the participants had no fillings with mean filled teeth of $2.74 \pm 4.2$. Approximately $77 \%$ had 3 to 6 AOP while only $58 \%$ had 4 to 8 POP. Mean AOP was $4.4 \pm 2.3$ and mean POP was $4.2 \pm 3.1$. Out of the 94 participants, 14 (15\%) were edentulous of which 8 wore complete dentures. 
Table 1: Demographics and dentition status

\begin{tabular}{|c|c|}
\hline Variable & $N(\%)$ \\
\hline \multicolumn{2}{|l|}{ Sex } \\
\hline Males & $56(58.3)$ \\
\hline Females & $37(38.5)$ \\
\hline Missing & $03(3.2)$ \\
\hline \multicolumn{2}{|l|}{ Race/ethnicity } \\
\hline American Indian/Alaskan native & $02(2.1)$ \\
\hline African American & $36(37.5)$ \\
\hline White & $46(47.9)$ \\
\hline Hispanic or Latino & $11(11.5)$ \\
\hline Missing & $01(1.0)$ \\
\hline \multicolumn{2}{|l|}{ Years on dialysis } \\
\hline $0-3$ & $56(58.3)$ \\
\hline$>3$ & $39(40.6)$ \\
\hline Missing & $01(1.0)$ \\
\hline Mean & $4.34 \pm 6.6$ \\
\hline \multicolumn{2}{|l|}{ Age (years) } \\
\hline$<65$ & $42(43.8)$ \\
\hline$\geq 65$ & $51(53.1)$ \\
\hline Missing & $03(3.1)$ \\
\hline Mean & $64.81 \pm 12.9$ \\
\hline \multicolumn{2}{|l|}{ Co-morbidities } \\
\hline 1 & $56(58.3)$ \\
\hline More than 1 & $37(38.5)$ \\
\hline Missing & $03(3.1)$ \\
\hline \multicolumn{2}{|l|}{ Teeth present } \\
\hline 0-19 & $38(39.6)$ \\
\hline $20-32$ & $56(58.3)$ \\
\hline Missing & $02(2.1)$ \\
\hline Mean & $20.12 \pm 10.8$ \\
\hline \multicolumn{2}{|l|}{ Decayed teeth } \\
\hline 0 & $49(51.0)$ \\
\hline$\geq 1$ & $45(46.9)$ \\
\hline Missing & $02(2.1)$ \\
\hline Mean & $1.52 \pm 2.72$ \\
\hline \multicolumn{2}{|l|}{ Filled teeth } \\
\hline No fillings & $45(46.8)$ \\
\hline $1-3$ teeth & $17(17.7)$ \\
\hline 4-8 teeth & $15(15.6)$ \\
\hline 9 and above & $12(12.5)$ \\
\hline Missing & $07(7.3)$ \\
\hline Mean & $2.74 \pm 4.2$ \\
\hline \multicolumn{2}{|l|}{ CPI } \\
\hline 0 & $8(8.5)$ \\
\hline $1-4$ & $50(53.2)$ \\
\hline Missing & $36(38.3)$ \\
\hline \multicolumn{2}{|l|}{ POPs } \\
\hline $0-3$ & $39(42.4)$ \\
\hline $4-8$ & $53(57.6)$ \\
\hline Mean & $4.2 \pm 3.1$ \\
\hline \multicolumn{2}{|l|}{ AOPs } \\
\hline $0-2$ & $22(23.4)$ \\
\hline $3-6$ & 72 (76.6) \\
\hline Mean & $4.4 \pm 2.3$ \\
\hline
\end{tabular}

Table 2 presents the association between AOPs and individual GOHAl-12 items and GOHAl-12 dimensions. Median GOHAl-12 score was 52 with an interquartile range (IQR) of 40 and 56 . Two item scores within physical dimension-limiting the kinds or amounts of food $(p=0.040)$ and trouble biting or chewing any
Table 2: Comparison of GOHAI-12 item scores by AOP among patients receiving hemodialysis

\begin{tabular}{|c|c|c|c|}
\hline GOHAl-12 items & $\begin{array}{l}A O P 0-2 \\
N=22\end{array}$ & $\begin{array}{l}A O P 3-6 \\
N=71\end{array}$ & $p$ value \\
\hline & Median (IQR) & Median (IQR) & \\
\hline Physical function & $15.5(11.5,20)$ & $18(15,20)$ & 0.067 \\
\hline $\begin{array}{l}\text { Limit the kinds or } \\
\text { amounts of food } \\
\text { you eat }\end{array}$ & $3(2,5)$ & $5(3,5)$ & $0.040^{*}$ \\
\hline $\begin{array}{l}\text { Trouble biting or } \\
\text { chewing any kinds } \\
\text { of foods }\end{array}$ & $2(2,5)$ & $5(3,5)$ & $0.010^{*}$ \\
\hline $\begin{array}{l}\text { Swallow } \\
\text { comfortably }\end{array}$ & $5(5,5)$ & $5(5,5)$ & 0.920 \\
\hline $\begin{array}{l}\text { Prevented from } \\
\text { speaking }\end{array}$ & $5(2.75,5)$ & $5(5,5)$ & 0.221 \\
\hline $\begin{array}{l}\text { Pain and } \\
\text { discomfort }\end{array}$ & $11.5(8,15)$ & $13(9.5,15)$ & 0.248 \\
\hline $\begin{array}{l}\text { Eating anything } \\
\text { without feeling } \\
\text { discomfort }\end{array}$ & $3(2,5)$ & $5(2,5)$ & 0.209 \\
\hline $\begin{array}{l}\text { Use medicates } \\
\text { to relieve pain or } \\
\text { discomfort }\end{array}$ & $5(3,5)$ & $5(4,5)$ & 0.354 \\
\hline $\begin{array}{l}\text { Teeth or gums } \\
\text { sensitive to hot, } \\
\text { cold, or sweets }\end{array}$ & $5(3,5)$ & $5(3,5)$ & 0.672 \\
\hline $\begin{array}{l}\text { Psychosocial } \\
\text { impacts }\end{array}$ & $19(13.25,22)$ & $22(18,25)$ & $0.041^{*}$ \\
\hline $\begin{array}{l}\text { Worried or } \\
\text { concerned }\end{array}$ & $3(1.75,5)$ & $5(3,5)$ & 0.316 \\
\hline $\begin{array}{l}\text { Feel nervous or } \\
\text { self-conscious }\end{array}$ & $5(2,5)$ & $5(3,5)$ & 0.415 \\
\hline $\begin{array}{l}\text { Feel uncomfortable } \\
\text { eating in front of } \\
\text { people }\end{array}$ & $4.5(2,5)$ & $5(5,5)$ & $0.024^{*}$ \\
\hline $\begin{array}{l}\text { Pleased or happy } \\
\text { with looks }\end{array}$ & $2(1,4)$ & $4(2,5)$ & $0.038^{*}$ \\
\hline $\begin{array}{l}\text { Limit contact with } \\
\text { people }\end{array}$ & $5(4.5,5)$ & $5(5,5)$ & 0.832 \\
\hline
\end{tabular}

${ }^{*} p<0.05$ Mann-Whitney UTest

kinds of foods ( $p=0.010$ )—were significantly associated with AOP; participants with AOPs 0 to 2 had lower median scores in the above items than participants with AOPs 3 to 6 . Within psychosocial impacts $(p=0.041)$, feeling uncomfortable eating in front of people ( $p=0.024)$ and pleased with looks $(p=0.038)$ were statistically significant for AOP groups.

Table 3 presents the association between POP and individual GOHAl-12 items and dimensions. Within physical function, only trouble biting or chewing any kinds of foods were significantly associated with POP ( $p$ 0.044); participants with POPs 0 to 3 had a lower median score and IQR of $3(2,5)$ as compared to participants with POPs 4 to 8 that had a median score and IQR of $5(3,5)$. Within psychosocial impacts, only pleased with looks showed significant association with POP groups ( $p$ 0.038); participants with POPs 0 to 3 had lower median scores of $2(1,5)$ in this item than participants with POPs 4 to 8 who had median scores of $4(2,5)$, and this difference was statistically significant. 
Table 3: Comparison of GOHAI-12 item scores by POP among patients receiving hemodialysis

\begin{tabular}{|c|c|c|c|}
\hline GOHAl-12 items & $\begin{array}{l}P O P 0-3 \\
N=39\end{array}$ & $\begin{array}{l}P O P 4-8 \\
N=52\end{array}$ & $p$ value \\
\hline & Median (IQR) & Median (IQR) & \\
\hline Physical function & $16(13,20)$ & $18(15,20)$ & 0.225 \\
\hline $\begin{array}{l}\text { Limit the kinds or } \\
\text { amounts of food you } \\
\text { eat }\end{array}$ & $5(2,5)$ & $5(3,5)$ & 0.410 \\
\hline $\begin{array}{l}\text { Trouble biting or } \\
\text { chewing any kinds of } \\
\text { foods }\end{array}$ & $3(2,5)$ & $5(3,5)$ & $0.044^{*}$ \\
\hline Swallow comfortably & $5(5,5)$ & $5(5,5)$ & 0.832 \\
\hline $\begin{array}{l}\text { Prevented from } \\
\text { speaking }\end{array}$ & $5(3,5)$ & $5(5,5)$ & 0.293 \\
\hline Pain and discomfort & $12(9,15)$ & $13(9.25,15)$ & 0.598 \\
\hline $\begin{array}{l}\text { Eating anything } \\
\text { without feeling } \\
\text { discomfort }\end{array}$ & $4(2,5)$ & $4(2,5)$ & 0.966 \\
\hline $\begin{array}{l}\text { Use medicates } \\
\text { to relieve pain or } \\
\text { discomfort }\end{array}$ & $5(3,5)$ & $5(5,5)$ & 0.264 \\
\hline $\begin{array}{l}\text { Teeth or gums } \\
\text { sensitive to hot, } \\
\text { cold or sweets }\end{array}$ & $5(3,5)$ & $5(3,5)$ & 0.800 \\
\hline $\begin{array}{l}\text { Psychosocial } \\
\text { impacts }\end{array}$ & $20(16,24)$ & $22(18,25)$ & 0.153 \\
\hline $\begin{array}{l}\text { Worried or } \\
\text { concerned }\end{array}$ & $5(2,5)$ & $4.5(3,5)$ & 0.910 \\
\hline $\begin{array}{l}\text { Feel nervous or } \\
\text { self-conscious }\end{array}$ & $5(3,5)$ & $5(3,5)$ & 0.860 \\
\hline $\begin{array}{l}\text { Feel uncomfortable } \\
\text { eating in front of } \\
\text { people }\end{array}$ & $5(3,5)$ & $5(5,5)$ & 0.253 \\
\hline $\begin{array}{l}\text { Pleased or happy } \\
\text { with looks }\end{array}$ & $2(1,5)$ & $4(2,5)$ & $0.038^{*}$ \\
\hline $\begin{array}{l}\text { Limit contact with } \\
\text { people }\end{array}$ & $5(5,5)$ & $5(5,5)$ & 0.832 \\
\hline
\end{tabular}

${ }^{*} p<0.05$ Mann-Whitney UTest

After adjusting for the effects of sex, age, race/ethnicity, presence of co-morbidities, and years on dialysis (Table 4), participants with AOPs 0 to 2 had $86 \%$ lower odds of reporting GOHAI-12 scores above 40 (25th percentile) than group with AOPs 3 to 6 (odds ratio $(\mathrm{OR})=0.14 ; 95 \%$ confidence interval $(\mathrm{Cl})=0.04-0.58$ ). However, none of the adjusted relationships between dichotomized GOHAI-12 and number of teeth, filled teeth, decayed teeth, or POPs was statistically significant.

Fig. 1 shows the distribution of the dental status of each tooth. The proportion of teeth present was higher for anterior teeth than posterior teeth in the upper arch while the proportion of teeth present in the lower arch was higher for anterior teeth and premolars as compared to molars. The proportion of fixed or removable prostheses replacing natural teeth was slightly higher for anterior teeth and premolars than posterior teeth in both upper and lower dental arches.
Table 4: Relationship between GOHAI-12 scores* and clinical status in hemodialysis participants

\begin{tabular}{llll}
\hline Variables & $N$ & $O R(95 \% \mathrm{Cl})$ & p value \\
\hline Number of teeth & & & \\
$0-19$ & 37 & $0.4(0.13-1.13)$ & 0.084 \\
20 and above & 51 & 1 & \\
Filled teeth & & & \\
No fillings & 45 & 1 & \\
1-3 teeth & 16 & $0.78(0.22-2.78)$ & 0.697 \\
4-8 teeth & 14 & $6.09(0.7-53.7)$ & 0.104 \\
9 and above & 12 & $4.42(0.47-41.26)$ & 0.193 \\
Decayed teeth & & & \\
No decayed teeth & 46 & 1 & \\
$\geq 1$ decayed teeth & 42 & $0.36(0.13-1.06)$ & 0.063 \\
AOPs & & & \\
0-2 & 22 & $0.14(0.04-0.58)$ & $0.006 \wedge$ \\
3-6 & 66 & 1 & \\
POPs & & & \\
$0-3$ & 37 & $0.39(0.13-1.20)$ & 0.099 \\
$4-10$ & 49 & 1 & \\
\hline
\end{tabular}

${ }^{*} \mathrm{GOHAl}-12$ score dichotomized using the 25th percentile (GOHAl-12 score $=40$ ); adjusted for sex, age group, race/ethnicity, presence of comorbidities, and years on dialysis; $\wedge p<0.05$

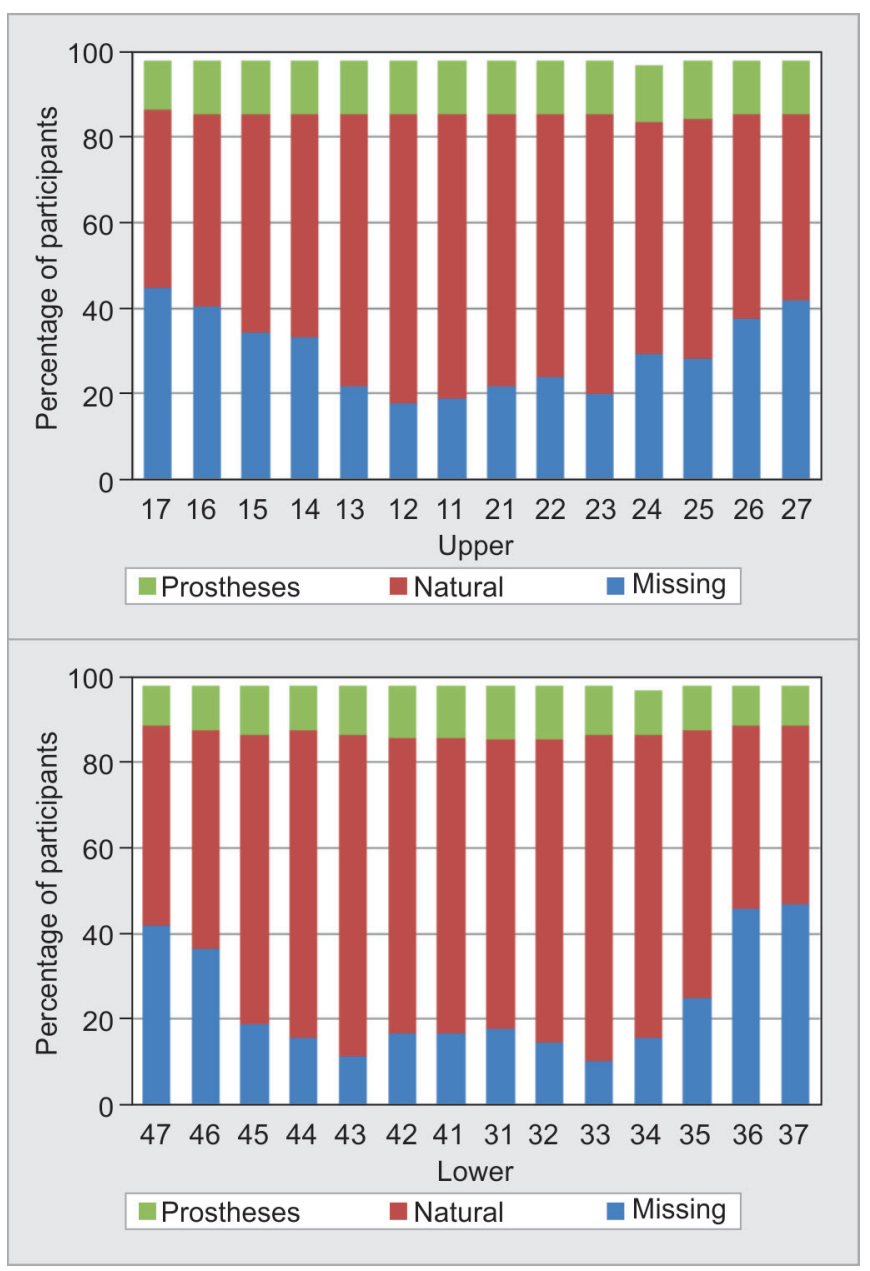

Fig. 1: Distribution of dental status at individual teeth 


\section{Discussion}

The bidirectional relationship between oral and general health can have profound effect on management and treatment outcomes among patients on hemodialysis. Beyond the pain and discomfort, of poor oral health, the effect on eating, and thereby dietary adherence as well as communication can influence the individual's social roles. The study demonstrated an association between occluding pairs of teeth and subjective measures of OHRQoL among patients receiving hemodialysis. After adjusting for sex, age, race/ ethnicity, presence of co-morbidities, and years on dialysis, patients with AOP 2 or fewer than 2 had $86 \%$ lower odds of reporting GOHAI12 score above 40 . The significant association between AOP and OHRQoL is in agreement with findings of the previous studies ${ }^{12,14,26}$ where subjective experiences of higher oral impact were associated with AOP. Our study observed that fewer AOP have a larger effect than POP not only in the psychosocial dimension but also in the functional abilities. To our knowledge, this study is one of the first few studies to look at location and distribution of occluding pairs with subjective experiences in dialysis patients in the United States.

Locker $^{26}$ and Tsakos et al. ${ }^{12}$ emphasize that the presence of disease does not necessarily affect subjective experience of wellness, and even when it does, its effect is influenced by the nature of the disease, the context of culture, and value systems in which individuals live and access to financial, social, and psychological resources. Patients undergoing dialysis reported a high median GOHAI-12 score of 52 which did not reflect the poor oral health that the clinical examinations revealed. Nearly $48 \%$ had at least one decayed tooth and $86 \%$ of those examined for periodontal health had some form of periodontal disease. This suggests that in our sample, dental caries or presence of gingival bleeding, calculus, or pockets do not affect subjective experiences of well-being also aligning with previous studies that showed the presence of periodontal diseases or dental caries to have no or minimal effect on subjective experiences of oral impacts. ${ }^{11,28,29}$ Oral diseases leading to ultimate tooth loss affect OHRQoL when tooth loss impacts social well-being and limits oral functions. This finding reconfirms the difference between disease and health. ${ }^{12}$ As Vingilis and Sarkella ${ }^{29}$ assert clinical indicators measure disease while subjective experiences of wellness and the absence of functional disabilities define health. Oral diseases such as dental caries and periodontal disease remain latent before causing symptoms. People are unlikely to experience functional limitations, pain, or discomfort until the disease has progressed to symptomatic stage. Dental diseases are cumulative and it is the ultimate loss of tooth that affects subjective well-being or functional impairment. ${ }^{12}$

In the study sample of dentate patients, the average missing teeth were $8.4 \pm 7.2$. Patients may have accrued tooth loss over a period of time. They are likely to have adapted to their oral impairments and may have made gradual dietary changes as Millwood et al. in their study point out ${ }^{30}$ Also, with more serious general health concerns, their health priorities are not focused on oral health. ${ }^{28,32}$ In our study, we observed that the loss of anterior teeth had a greater impact than the loss of posterior teeth and that patients experienced psychosocial impact in addition to physical impairments. GOHAI-12 scores were significantly lower for patients with AOP 2 or less than 2 for two psychosocial impacts (not happy with looks and uncomfortable eating in front of others) and two physical functions (limiting foods and trouble biting/chewing). Patients with POP 3 or less than 3 reported significantly lower GOHAl-12 scores for unhappy with looks and trouble biting/chewing. This finding is congruent with previous studies ${ }^{33,34}$ that found psychological impacts to be reported alongside physical oral impairments even with instruments like GOHAl-12 that gives greater weight to functional dimensions of oral impacts.

While this study enhances our understanding regarding the relationship between patients' oral health and general health, it was not without limitations. While evidence suggests POP to be associated with some items within GOHAI-12 in bivariate analyses but not in regression analyses, it may be that the study did not have enough statistical power to investigate all exposures. Generalization warrants some caution as convenience sampling of hemodialysis patients may not be true for all hemodialysis patients. Social desirability may have incorporated some response bias in the study and finally, even though the dental hygienist and dental assistant were calibrated, inter- and intra-rater reliability were not determined given the nature of the setting in which the data collection took place and to minimize the burden on dialysis patients. History of tooth loss in edentate patients was not elicited and recorded.

This study highlights AOP (location and distribution of teeth) to affect subjective experiences among hemodialysis patients. The implications for clinical practice, research as well as public health policy lend to the need for a comprehensive assessment of subjective health in concert with objective measures. Care pathways may help inform public policy for oral health care in hemodialysis patients as recommended by Pretty et al. ${ }^{34}$ Oral health prevention and promotion programs aimed at reducing tooth loss need to be reinforced among those living with chronic diseases. Using the common risk factor approach and targeting common risk factors, preventive strategies should be prioritized by policymakers as suggested by Peterson and Yamamoto. ${ }^{1}$ An increasing number of older adults are retaining their natural teeth for a longer period in life and living with chronic diseases. Not only will dentists see more patients living with chronic diseases but also there will be greater demand for conservative treatment aimed at preserving teeth. ${ }^{1,36,37}$ Further, while treatment and management of oral health problems in dialysis patients are complicated by the presence of co-morbidities, age-related changes in the mouth, and issues of access to dental care, identification, repair, or replacement of strategically important teeth using the "shortened dental arch principle" to maintain oral function among hemodialysis patients are recommended, ${ }^{35,38-40}$ yet the effectiveness of preventive strategies and economic analyses of tooth repair and replacement strategies will require further research.

\section{ConClusion}

Lower GOHAI-12 scores were associated with AOP 2 or less than 2 in the study sample. Maintenance and improvement of oral function through oral health prevention and promotion programs as well as purposeful replacement of important teeth using the "shortened dental arch principle" are recommended in dialysis patients.

\section{ACKNowledgments}

The study was funded by Inter-professional Practice Grant (20162017) from Elaine Nicpon Marieb College of Health and Human Services, Florida Gulf Coast University.

\section{References}

1. Petersen PE, Yamamoto T. Improving the oral health of older people: the approach of the WHO global oral health programme. Community Dent Oral Epidemiol 2005;33(2):81-92. DOI: 10.1111/j.16000528.2004.00219.x. 
2. Naugle K, Darby ML, Bauman DB, et al. The oral health status of individuals on renal dialysis. Ann Periodontol 1998;3(1):197-205. DOI: 10.1902/annals.1998.3.1.197.

3. Chamani G, Zarei MR, Radvar M, et al. Oral health status of dialysis patients based on their renal dialysis history in Kerman, Iran. Oral Health Prev Dent 2009;7(3):269-275. PMID: 19780434.

4. Souza CM, Braosi APR, Luczyszyn SM, et al. Oral health in Brazilian patients with chronic renal disease. Rev Med Chile 2008;136(6):741746. DOI: $10.4067 /$ S0034-98872008000600008.

5. Mechanic D. Emerging trends in the application of the social sciences to health and medicine. Soc Sci Med 1995;40(11):1491-1496. DOI: 10.1016/0277-9536(95)00024-2.

6. Wilson IB, Cleary PD. Linking clinical variables with health-related quality of life: a conceptual model of patient outcomes. JAMA 1995;273(1):59-65. DOI: 10.1001/jama.1995.03520250075037.

7. Decker SD, Schultz R, Wood D. Determinants of well-being in primary caregivers of spinal cord injured persons. Rehabil Nurs 1989;14(1):6-8. DOI: 10.1002/j.2048-7940.1989.tb00664.x.

8. Sprangers MAG, Aaronson NK. The role of health care providers and significant others in evaluating the quality of life of patients with chronic disease: a review. J Clin Epidemiol 1992;45(7):743-760. DOI: 10.1016/0895-4356(92)90052-O.

9. Kralik D, van Loon A, Visentin K. Resilience in the chronic illness experience. Educ Action Res 2006;14(2):187-201. DOI: 10.1080/09650790600718035.

10. Gerritsen AE, Allen PF, Witter DJ, et al. Tooth loss and oral healthrelated quality of life: A systematic review and meta-analysis. Health Qual Life Outcomes 2010;8(1):126. DOI: 10.1186/1477-7525-8-126.

11. Rodakowska E, Wilczyńska-Borawska M, Fryc J, et al. Oral healthrelated quality of life in patients undergoing chronic hemodialysis. Patient Prefer Adherence 2018;12:955-961. DOI: 10.2147/PPA.S161638.

12. Tsakos G, Steele JG, Marcenes W, et al. Clinical correlates of oral healthrelated quality of life: evidence from a national sample of British older people. Eur J Oral Sci 2006;114(5):391-395. DOI: 10.1111/j.16000722.2006.00398.x.

13. Baba $K$, Igarashi $Y$, Nishiyama A, et al. Patterns of missing occlusal units and oral health-related quality of life in SDA patients. J Oral Rehabil 2008;35(8):621-628. DOI: 10.1111/j.1365-2842.2007.

14. Pallegedara C, Ekanayake L. Effect of tooth loss and denture status on oral health-related quality of life of older individuals from Sri Lanka. Community Dent Health 2008;25(4):196. PMID: 19149294.

15. Atchison KA, Dolan TA. Development of the geriatric oral health assessment index. J Dent Educ 1990;54(11):680-687. PMID: 2229624.

16. Kressin NR, Atchison KA, Miller DR. Comparing the impact of oral disease in two populations of older adults: application of the geriatric oral health assessment index. J Public Health Dent 1997;57(4):224232. DOI: $10.1111 /$ j.1752-7325.1997.tb02979.x.

17. Ekanayake L, Perera I.The association between clinical oral health status and oral impacts experienced by older individuals in Sri Lanka. J Oral Rehabil 2004;31(9):831-836. DOI: 10.1111/j.1365-2842.2004.01311.x.

18. Ashing-Giwa KT, Tejero JS, Kim J, et al. Examining predictive models of HRQOL in a population-based, multiethnic sample of women with breast carcinoma. Qual Life Res 2007;16(3):413-428. DOI: 10.1007/ s11136-006-9138-4.

19. Baba K, Igarashi Y, Nishiyama A, et al. The relationship between missing occlusal units and oral health-related quality of life in patients with shortened dental arches. Int J Prosthodont 2008;21(1):72. DOI: 10.1111/j.1365-2842.2007.01803.x.

20. Mesas AE, De Andrade SM, Cabrera MAS. Factors associated with negative self-perception of oral health among elderly people in a Brazilian community. Gerodontology 2008;25(1):49-56. Available from: https://onlinelibrary.wiley.com/doi/abs/10.1111/j.1741-2358. 2007.00196.x. DOI: 10.1111/j.1741-2358.2007.00196.x.

21. World Health Organization. Oral health surveys: basic methods. Albany: World Health Organization; 2013.

22. Sheiham A, Steele JG, Marcenes W, et al. The impact of oral health on stated ability to eat certain foods; findings from the national diet and nutrition survey of older people in Great Britain.
Gerodontology 1999;16(1):11-20. PMID: 10687504. DOI: 10.1111/j.17412358.1999.00011.x.

23. Agerberg G, Carlsson GE. Chewing ability in relation to dental and general health. Acta Odontol Scand 1981;39(3):147-153. DOI: 10.3109/00016358109162273.

24. Tsakos G, Marcenes W, Sheiham A. The relationship between clinical dental status and oral impacts in an elderly population. Oral Health Prev Dent 2004;2(3):211. PMID: 15641624.

25. Tan H, Peres KG, Peres MA. Retention of teeth and oral health-related quality of life. J Dent Res 2016;95(12):1350-1357. Available from: https://search.datacite.org/works/10.1177/0022034516657992. DOI: $10.1177 / 0022034516657992$

26. Locker $\mathrm{D}$. The burden of oral disorders in a population of older adults. Community Dent Health 1992;9(2):109. PMID: 1504877.

27. Schmalz G, Kollmar O, Vasko R, et al. Oral health-related quality of life in patients on chronic haemodialysis and after kidney transplantation. Oral Dis 2016;22(7):665-672. Available from: https://onlinelibrary. wiley.com/doi/abs/10.1111/odi.12519. DOI: 10.1111/odi.12519.

28. Kahar P, Chapman C, Gupta J. Assessment of the effect of oral health on quality of life and oral-health indicators among ESRD patients in southwest Florida: a pilot study. Int J Dent 2019;2019:1-9. Available from: https://search.datacite.org/works/10.1155/2019/1608329. DOI: 10.1155/2019/1608329.

29. Vingilis E, Sarkella, J.Determinants and indicators of health and well-being: tools for educating society. Soc Indic Res 1997;40(1/2):159-178. Available from: https://www.jstor.org/stable/27522971. DOI: 1006855410848.

30. Millwood J, Heath MR. Food choice by older people: the use of semi-structured interviews with open and closed questions. Gerodontology 2000;17(1):25-32. Available from: https://search. datacite.org/works/10.1111/j.1741-2358.2000.00025.x. DOI: 10.1111/j.1741-2358.2000.00025.x.

31. Klassen JT, Krasko BM. The dental health status of dialysis patients. J Can Dent Assoc 2002;68(1):34-38. PMID: 11844416.

32. Locker D, Matear D, Stephens M, et al. Comparison of the GOHAI and OHIP-14 as measures of the oral health-related quality of life of the elderly. Community Dent Oral Epidemiol 2001;29(5):373-381. PMID: 11553110. DOI: 10.1034/j.1600-0528.2001.290507.x.

33. Walker RJ, Kiyak HA. The impact of providing dental services to frail older adults: Perceptions of elders in adult day health centers. Spec Care Dentist 2007;27(4):139-143. DOI: 10.1111/j.1754-4505.2007.tb00336.x.

34. Pretty IA, Ellwood RP, Lo ECM, et al. The Seattle care pathway for securing oral health in older patients. Gerodontology 2014;31(s1):7787. Available from: https://onlinelibrary.wiley.com/doi/abs/10.1111/ ger.12098. DOI: 10.1111/ger.12098.

35. Palmqvist S, Söderfeldt B, Arnbjerg D. Self-assessment of dental conditions: validity of a questionnaire. Community Dent Oral Epidemiol 1991;19(5):249-251. Available from: https://onlinelibrary. wiley.com/doi/abs/10.1111/j.1600-0528.1991.tb00160.x. DOI: 10.1111/ j.1600-0528.1991.tb00160.x.

36. Petersen PE. The world oral health report 2003: continuous improvement of oral health in the 21st century - the approach of the WHO global oral health programme. Community Dent Oral Epidemiol 2003;31(s1):3-24. https://search.datacite.org/works/10.1046/j..2003. com122.x. DOI: 10.1046/j.2003.com122.x.

37. Heath MR, Wright P. The teaching of prosthodontic care for older people: a non-rote philosophy. Gerodontology 1997;14(2):113-118. Available from: https://onlinelibrary.wiley.com/doi/abs/10.1111/j.17412358.1997.00113.x. DOI: 10.1111/j.1741-2358.1997.00113.x.

38. Gerritsen AE, Witter DJ, Bronkhorst EM, et al. An observational cohort study on shortened dental arches - clinical course during a period of 27-35 years. Clin Oral Invest 2012;17(3):859-866. DOI: 10.1007/ s00784-012-0765-6.

39. Griffin SO, Jones JA, Brunson D, et al. Burden of oral disease among older adults and implications for public health priorities. Am J Public Health 2012;102(3):411-418. Available from: https://search.datacite. org/works/10.2105/ajph.2011.300362. DOI: 10.2105/ajph.2011.300362.

40. Thomson WM, Ma S. An ageing population poses dental challenges. Singapore Dent J 2014;35:3-8. DOI: 10.1016/j.sdj.2014.10.001. 